\title{
Desafíos planteados a la Iglesia y a la sociedad por la pandemia del VIH/SIDA*
}

\section{Julian Filochowski, CAFOD, Londres.}

\section{Introducción}

Para mí es un gran honor -aunque me siento también un poco abrumadotener la oportunidad de decir unas palabras al iniciar estos días de reflexión. El lema nos afecta a todos, en todas las partes del mundo, en todos los niveles de la vida, en todas las clases sociales y económicas, desde el más poderoso jefe de Estado hasta la persona más pobre y marginada de la sociedad. Estamos aquí para reflexionar sobre las consecuencias, tanto para la Iglesia como para la sociedad en general, de un fenómeno que, a pesar de haber sido identificado sólo recientemente, está produciendo ya sus trágicos efectos y a una velocidad alarmante: el fenómeno del VIH/SIDA.

Al comenzar esta ponencia, soy consciente de que estamos reunidos en una parte del mundo, en un país y en una ciudad, San Salvador, que ha visto y ha sentido en un pasado no lan lejano el testimonio de muchos mártires torturados y asesinados por causa de la justicia y de la liberación de los oprimidos; martirizados por la fe cristiana y por la convicción de que Dios otorga a todo ser humano una dignidad única, que no puede ser amenazada, ni por el poder, ni por la codicia de otros. En este momento, recuerdo con cariño y con tristeza el valiente lestimonio de mi amigo Monseñor Romero, quien arriesgó su vida y murió asesinado por permanecer fiel al mandato del evangelio: que toda la Iglesia y todos sus miembros hagan y mantengan una opción preferencial por los más pobres y vulnerables de nuestro mundo.

* Ponencia de apertura de la "Consulta de Teólogos Latinoamericanos sobre el VIH/ SIDA - Carilas Internationalis", celebrada en San Salvador del 3 al 7 de septiembre de 2001. El autor desea expresar su agradecimiento a la Dra. Ann Smith y el Padre Robert Vitillo por sus valiosos aportes en la elaboración del esquema inicial del texto. 
En este contexto, pudiéramos preguntarnos, con razón, si en este continente y en otras partes del mundo la sangre de tantos mántires se ha derramado en vano, puesto que continúa el sufrimiento de los pobres, persiste la opresión y el abuso de los derechos humanos de personas que no pueden protesiar y el escándalo de la codicia aplastante de aquellos que ya tienen demasiado en este mundo, mientras las grandes mayorías pasan hambre y no tienen lo mínimo para asegurarse una vida digna.

Muy probablemente estas injusticias son las que el Papa Juan Pablo II tenía presentes cuando clausuró el Año Jubilar e inauguró el Tercer Milenio Cristiano con las siguientes palabras de su Carta Apostólica Tertio Millennio Ineunte:

Nuestro mundo está a punto de entrar en un nuevo milenio cargado con las contradicciones de un avance económico, cultural y tecnológico que ofrece posibilidades inmensas a los afortunados que son pocos, mientras que millones de otros se quedan no solamente en los márgenes del progreso, sino en condiciones de vida mucho más bajas que las mínimas exigidas por la dignidad humana. ¿Cómo puede ser que todavía hoy hay personas que se mueren de hambre, que están condenadas al analfabetismo, a quienes les falta la más básica atención médica?

Los cristianos deben aprender a hacer real su fe en Crislo, escuchando su voz en el grito que se eleva de este mundo de pobreza... Ya es hora de una nueva crealividad en la solidaridad, no sólo para asegurar que la ayuda sea elicaz, sino también para acercarse a los que sufren, para que no perciban la Inano que ayuda como gesto humillante de caridad, sino como modo de compartir entre hermanos y hermanas (Tertio Millennio Ineunte, N. 50).

Cuando vemos estos y otros graves problemas sociales y económicos, con los cuales el mundo actual se enfrenta, especialmente los pobres, pudiéramos preguntarnos si es necesario, o apropiado, dedicar a la problemática del VIH/SIDA tanto tiempo, tanta energía y tantos conocimientos. Sin embargo, es mi convicción —sobre lodo en este continente de América Latina- que dedicarse seriamente a este problema es muy necesario, apropiado y hasta imprescindible. Aquí, como en otras partes, la pandemia del VIH/SIDA va muy unida, de modo inseparable, al pecado de la injusticia estructural, al abuso de poder, en especial en las relaciones entre el hombre y la mujer y en el tratamiento al marginado, a la lalta de respeto a los derechos humanos y a la dignidad humana, a la falta de soluciones a las necesidades más básicas de la vida humana. Resumamos, recordando las palabras de Juan Pablo II: "la cultura reinante de la muerte es la plaga de la sociedad contemporánea".

Por eso, cs bueno que tengamos esta consulta sobre el VIH/SIDA, en esta parte del mundo, que es pobre, pero también en un pueblo de le, que fue como la partera. la madrina, del compromiso de la Iglesia católica, articulado en las 
últimas décadas del siglo XX como opción prelerencial por los pobres. Esperamos que América Latina pueda ayudar a comunicar a la Iglesia y al resto del mundo la verdad sobre lá siluación de las personas alectadas por el sufrimiento y la Irilgedia de la pandemia del VIH/SIDA, y llame a todos los fieles a comprometerse, Inás aún. a denunciar las injuslicias y desigualdades que el VIH saca a luz y a olrecer una respuesta de compasión, sin juzgar a las personas alectadas.

Todavía recuerdo, con algo de humor. mi primera conversación sobre el VIH/ SIDA con mi buen amigo el cardenal Arns de Brasil hacia linales de los ochenla. Cuando le sugerí la necesidad de una respuesta arquidiocesana a la pandemia, Dom Paulo me dijo que, en su opinión, ésa era una enfermedad de la clase media, la cual ya contaba con los amplios recursos de los privilegiados. Por eso, no le parecía justilicable dar una respuesta prioritaria a cse problema, pues la Iglesia tenía como primera responsabilidad dar respuesta a los problemas de los pobres. De iodos modos, cl cardenal se comprometió a hacer una consulta entre los agentes de pastoral que trabajaban en el apostolado con niños de la calle y con prostitutas. El carclenal se dio cuenta de la vulnerabilidad de estos pobres, en particular con respecio al VIH/SIDA, cambió de opinión y, desde entonces, ha defendido incansablemente a los afectados por el VIH/SIDA y, sobre todo, sus derechos humanos.

\section{Las dimensiones de la propagación global del VIH/SIDA}

Veamos ahora la situación actual de la pandemia en el mundo para poder apreciar la necesidad de una urgente respuesta a tantas personas, cuyas vidas han sido afecladas por el "Virus de la Inmunodeficiencia Humana". La magnilud y las consecuencias trágicas del VIH/SIDA llegarán a sobrepasar las de todas las pandemias previas en la historia de la humanidad (incluyendo la reaparición de la peste bubónica de la edad media y la epidemia de gripe de 19/8). A pesar de que se ha descubierto sólo hace veinte años, el VIH ya es el virus más poderoso y contagioso, que desafía a la medicina moderna. En la actualidad es la cuarta causa de muerte en el mundo. El SIDA se sigue extendiendo inexorablemente por todo el globo sin perdonar a ningún país. No existe cura, ni vacuna, y todavía no se le ve lin.

En diciembre del año 2000, la Organización Mundial de la Salud informó que más de 36 millones de hombres, mujeres y niños en el mundo vivían con el VIH o SIDA, y que casi 22 millones ya hablan muerto de esa enfermedad. En el año milenario, aproximadamente 5.3 millones de personas se contagiaron del VIH a nivel mundial (más de 15,000 al día) y 3 millones murieron ese mismo año.

Hasta ahora, el VIH/SIDA ha golpeado con mayor fuerza a Africa. El 70 por ciento de todos los adultos y el 80 por ciento de los niños que viven con VIH están allí. El SIDA es la primera causa de muerte en Africa, responsable del 20 por ciento de todos los fallecimientos en ese continente. El año pasado, 2.4 millones de africanos murieron por causa del SIDA y 3.8 millones se contagia- 
ron del VIH. En siete países del Africa austral, al menos uno de cada cinco adultos vive con el virus. Los países africanos agonizan por el impacto de la enfermedad.

La pandemia está creciendo sin cesar y de forma alarmante en Asia, donde más de 900,000 personas quedaron infectadas el año pasado. Muchos creen que las estadísticas oficiales de India subestiman la verdadera situación, y muchos trabajadores de pastoral creen que en ese país existen ya más personas infectadas del VIH que en cualquier otro país. Todo esto confirmaría el pronóstico de que, dentro de una década, India, junto con el resto del sur y sudeste de Asia, sustituirá a Africa como el epicentro de la pandemia.

América Latina y el Caribe tampoco se han salvado de los efectos del VIH/ SIDA. La propagación de la epidemia en esta región se debe a un complejo mosaico de comportamientos, que incluyen sexo entre hombres, sexo entre homhics y mujeres, y uso de drogas inyectadas. Se calcula que 150,000 adultos y niños se contagiaron durante el año 2000 , llegando cl total de personas infectadas en esta región a casi un millón y medio. Brasil, el país con la mayor población de la región, tiene el número más alto de personas con VIH: 540,000. El Caribe tiene la tasa más alta de infección del VIH en el mundo después del Alrica subsahariana; el SIDA ya es la primera causa de muere entre los jóvenes de la zona. Los países centroancricanos, destrozados por años de conllicto armado, por la destrucción del medio ambiente y por un crecimiento económico excluyente, han experimentado una tasa creciente de infección, en particular entre los seclores más pobres de la población y entre las mujeres'.

Incluso en algunas partes del continente, donde el índice de la infección pircciera ser tan bajo como para no tener importancia, sería un error muy grave subestimar la epidemia como algo irrelevante, diciendo que "no tiene nada que ver con nosolros". Precisamente, en situaciones como ésas el VIH ha llegado a ser una silenciosa epidemia, que es desconocida y pasa desapercibida. lo cual. cn muchos sentidos, la hace más peligroso. En el continente latinoamericano sc Jan todas las condiciones para que esta epidemia todavía desconocida empeore: la pobreza, el conflicto, los desastres naturales, la migración por razoncs econóinicas y políticas, el crecimiento en el consumo de las drogas, incluyendo las inyectadas, el aumento de la violencia física y sexual, la legislación discriminaloria y las desigualdades de género. reforzadas por un machismo que tiene profundas raíces. La conclusión es que en América Latina no se debe evaluar la seriedad del VIH solatnente por lo que dicen las estadísticas oficiales (siempre y en todas partes las cifias son demasiado bajas y, por lo tanto, una fuente de valor limitado), sino también por la preponderancia de las condiciones subyacentes, que

1. United Nations General Assembly. Special Session of the General Assembly on HIV/ AIDS: Report of the Secretary-General, A/55/779. p. 4. 
fomentan la vulnerabilidad a la infección. La siguiente historia, que cuenta una Irabajadora social de Honduras, María Ester Artiles, lo muestra con elocuencia:

El huracán Mitch asoló Honduras, causó aproximadamente cinco mil millones de dólares de daños y afectó a más de medio millón de los seis millones de habitantes del país. Por todo el país, los hondureños se quedaron sin casa, sin trabajo, sin tierra buena para cultivar y sin infraestructura. El desasire golpeó con mayor fuerza a la mayoría de la población pobre y urbana del país. Antes del huracán Mitch, Honduras ya tenía una de las tasas más altas de infección del VIH entre los países de Centroamérica, en tercer lugar después de las Guayanas y Belice. Calculando por lo bajo, había aproximadamente 40,000 personas inlectadas, por lo general entre 15 y 29 años de edad.

El Mitch afectó de varias maneras la pervivencia del VIH y la atención y el apoyo disponibles a personas que viven con él. La infraestructura de salud quedó muy destruida y los trabajadores de salud se centraron en responder a los problemas que resultaron del desastre, como por ejemplo las infecciones palúdicas, causadas por la destrucción de los servicios sanitarios. Las organizaciones no gubernamentales suspendieron sus programas de prevención del VIH para poder suministrar alimentación, abrigo y atención paliativa a corto plazo.

El Mitch tuvo otro tipo de impacto relacionado con las condiciones sociales y económicas ya existentes. Incluso antes del huracán, Honduras era uno de los países más pobres de Centroamérica. A raiz de ello aumentó el número de niños trabajadores y creció el número de niñas y mujeres jóvenes dedicadas en trabajo sexual. Los niños que quedaron sin casa y vivían en las calles de las ciudades del país estaban (y están) en mayor peligro de explotación sexual y violencia.

A largo plazo es muy poco probable que la vulnerabilidad social y los riesgos del VIH disminuyan. Las aclividades de reconstrucción se han centrado casi en su totalidad en la infraestructura física. dejando de lado otras formas de vulnerabilidad, incluyendo el VIH/SIDA.

En el luturo que se avecina, el impacto demográlico global del SIDA será impresionante, y ya ahora la esperanza de vida está descendiendo aceleradamentc. en los países más golpeados. En casi lodos los países que cuentan con más del 15 por ciento de la población adulta infectada del VIH, al menos el cincuenla por ciento de los jóvenes que cumplen quince años de edad morirán de SIDA. Es difícil prever el impacto social de este cambio en las estructuras demográlicas. Sabemos con seguridad que un grupo más reducido de adultos jóvenes tendrá que atender a un grupo cada vez mayor de jóvenes y ancianos.

Antes de la aparición del SIDA, aproximadamente el 2 por ciento de todos los niños en los países del sur quedaban huérfanos. En 1997. la proporción de niños menores de quince años que habían perdido a su madre o a los dos padres 
subió al 7 por ciento, en muchos países africanos, y en ciertos casos llegó al II por ciento. Hasta la fecha, la epidemia ha dejado a más de 13 millones de huérfanos, de los cuales el 95 por ciento vive en el Africa subsahariana. Solamente en la zona de Rakai, en Uganda, el 32 por ciento de la población menor de quince años —unos 75,000 niños- se ha quedado huérfanas. Hoy en día, en muchos países africanos, entre el 20 y el 25 por ciento de hogares acogen a huérfanos, y cientos de miles de hogares tienen jefes de familia con menos de quince años de edad.

Los hogares y las farnilias sufren gran parte del dolor de sus miembros afectaJos por el SIDA. Los que se enferman no pueden trabajar, lo que obliga a los otros miembros de la familia a cuidarlos, en vez de producir comida o ganarse la vida. Los pocos estudios que existen sobre el impacto de tener un miembro de la familia enfermo de SIDA muestran que ésta sufre una reducción dramática del ingreso. Por cjemplo, en las zonas urbanas de Costa de Marfil, la inversión en la educación formal de tales farnilias se redujo a la milad, el consumo de comida bajó en un $\mathbf{4 0}$ por ciento per cápita, y el gasto en salud se multiplicó por cuatro. El SIDA reduce el número de trabajadores sanos y expertos, en sus años más activos. El número de prolesores está bajando en todas partes y el tamaño de las aulas está creciendo. En Zambia, por ejemplo, durante los primeros diez meses del año 1999, 1,300 prolesorcs murieron de infecciones oportunistas, vinculadas al SIDA.

Además del impacto en la economia, la salud y el desarrollo, en enero del año 2000, el Consejo de Seguridad de Naciones Unidas reconoció que la epidemia del SIDA pone en peligro direclo la seguridad nacional e internacional. James Wollensohn, presidente del Banco Mundial, observó que la epidemia es más elicaz que la guerra para desestabilizar los países ${ }^{2}$. Se teme que el número creciente de huérfanos del SIDA ponga en peligro la scguridad en las ciudades y pueda nutrir a los ejércitos de niños que se agrupan en algunas partes del mundo.

La pandemia del VIH es una de las mayores crisis de salud, seguridad y desarrollo humano que enfrenta el planeta. Mata a millones de adultos en la flor de su vida. Quiebra y empobrece a familias, debilita la mano de obra, deja huérlanos a millones de niños y amenaza el tejido social y económico de las comunidades y la estabilidad política de las naciones. En sólo dos décadas, el SIDA ha llegado a ser una emergencia global de proporciones catastróficas.

\section{El papel de Caritas Internationalis en la respuesta de la Iglesia al VIH/ SIDA}

El compromiso de dar una respuesta decidida al VIH/SIDA por parte de Caritas Imternationalis tiene su origen en 1987, y sc mantiene hasta la fecha.

2. Harbara Crossette, "Gore Presides Over Rare Security Council Debate on AIDS". New York Times, January I1. 2000, p. A3. 
Caritas ha intentado ofrecer una respuesta educacional y de servicio a los desafíos de la pandemia, a través de las siguientes aclividades:

- La promoción de reuniones globales, regionales y nacionales (principalmente para gente de Iglesia).

- El establecimiento de un grupo de trabajo de expertos, que pueda proporcionar asistencia técnica y orientación a los interesados en organizar servicios de VIH/SIDA.

- La búsqueda de apoyo linanciero y de conocimientos prolesionales para apoyar cientos de proyectos de VIH/SIDA, patrocinados por la Iglesia, en Africa, Asia, América Latina, el Oriente Medio y el este de Europa.

Lo fundamental que hay que tener en cuenta es que la primera responsabilidad de la Iglesia es defender la vida de todas las personas. La Iglesia se ha preocupado por la salud física y espiritual, el bienestar de las personas y las comunidades. Se ha esforzado en declarar y propiciar el conjunto de valores que promueven y prolegen a estas personas y grupos. A través de su enseñanza, ha buscado promover y defender la integridad, la fidelidad y la responsabilidad dentro de las relaciones personales y formar las conciencias para poder conocer lo que Dios quiere ante las exigencias cotidianas de la vida social. Y sobre todo, ha afirmado el valor de toda vida humana, sin excepción. y la obligación de ponerse del lado de los que viven en peligro, sea cual fuere la razón?.

Precisamente porque la pandemia del VIH/SIDA amenaza la supervivencia ınisma de individuos, familias y comunidades, muchos insisten hoy en la misión lundamental que tiene la Iglesia de defender la vida y que, desde ahí, se desviva por ayudar en esta crisis. Y, además de la atención pastoral y la asistencia social exigidas, muchos ven en ello un signo de los tiempos, una llamada urgente a asegurar que la cnseñanza de la Iglesia proclame con toda claridad la responsabilidad lundamental de proteger la vida y, inás específicamente, de protegerla conlra la transmisión del VIH.

\section{Los problemas éticos planteados por la pandemia del VIH/SIDA}

\subsection{Acceso a los recursos económicos}

El mayor problema que plantea la pandemia del VIH/SIDA es la falta de justicia en la distribución de los bienes. El universo ha sido dolado con ricos recursos naturales por su Creador y el genio humano ha alcanzado nuevos logros tecnológicos y progresos culturales. Sin embargo, no todos los ciudadanos del inundo pueden aprovecharse de estos dones.

3. Evangelium Virae, N. 3. 
Los miembros pobies, marginados y oprimidos de la sociedad son también los más vulnerables a la amenaza del VIH y a las consecuencias trágicas del SIDA. Se ven privados del acceso a la educación preventiva, a la asistencia, al tratamiento y al apoyo que necesitan con urgencia. Basten estos dos datos para mostrarlo con claridad.

- Durante la década de los noventa la gran mayoría de personas infectadas del VIH vivían en los países del sur, pero el 95 por ciento de los 7 mil millones de dólares gastados en educación, asistencia y estudio sobre el SIDA fueron usados en el llamado mundo desarrollado o los países del norte ${ }^{4}$.

- En el año 2000 se calculó que los países alricanos necesilarían 1,500 inillones de dólares anuales para aclividades de prevención y así reducir signilicativamente el riesgo que el VIH presenta a sus habitantes (incluyendo niños. jóvenes, trabajadores y heneticiarios de transfusiones de sangre). Además. el presupuesto para la atención básica, la prevención de enlermedades oportunistas y la acogida de huérfanos supondría otros 1,500 millones. Tres mil inillones de dólares en total. Compárense estas ciliras con los 52 mil millones de dólares que se gastan al año en Estados Unidos para atender las consecuencias nocivas para la salud, producidas por la obesidad".

Las infecciones oportunistas, relacionadas con el VIH (tuberculosis, pulmonía, diarrea, eıc.), se pueden curar con eficacia y a bajo precio. Pero en muchos de los países más a feclados por el VIH, los botiquines de los hospitales están vacíos, e incluso carecen de los recursos más básicos. Las personas mueren cada día de enlermedades oportunistas, que se podrían curar por menos de lo que vale un periódico.

Las tan anunciadas drogas antiretrovirales han mejorado mucho la vida de las personas que las pueden obtener. El precio aproximado de un tralamiento anual (sin tomar en cuenta las reducciones -en diversos montos- acordadas recientemente por algunos países) oscila entre 10,000 y 15,000 dólares. Sin cmbargo, se ha calculado que solamente 400.000 de los 36 millones de personas inlectadas del VIH en el mundo tienen acceso a estas drogas, la mayor parte en los países que tienen sistemas de salud muy desarrollados y los recursos para comprarlas.

Algunos países de América Latina decidieron olrecer antiretrovirales a las personas seropositivas. En 1999. Brasil gastó 300 millones de dólares en drogas pura 75,000 personas. Los funcionarios sostienen que los fondos ahorrados al tener menos pacientes en los hospilales con enfermedades relacionadas con el VIH cubren la mayor parte de estos gastos. En Perú sólo hay antiretrovirales

4. UNAIDS, informes de julio y diciembre, 1996, sobre The Global Situation of AIDS.

5. UNAIDS. informe de diciembre, 2000, sobre The Global Siluation of AIDS. 
pal’a un número determinado de antemano de personas seroposilivas y los individuos son escogidos por un sistema parecido al de la lotería. En febrero del año 2000 la Comisión Interamericana de Derechos Humanos, con sede en WashingIon, tomó una decisión muy discutida, cuando ordenó al gobierno salvadoreño suministrar remedios antiretrovirales a 26 salvadoreños que habían presentado una deınanda judicial en septiembre del año anterior. Aunque hay que tener en cuenta la complejidad de los hechos, todos los debates sobre el acceso a antiretrovirales, apuntan al problema ético del desigual acceso a los recursos.

Para Lorena, las consecuencias de esta desigualdad son evidentes:

Lorena, una mujer nicaragüense de 37 años de edad, se ha convertido en un nuevo lipo de traficante. Viaja en los buses de Centroamérica buscando dónde comprar medicamentos para el SIDA, en el mercado negro, que ha florecido como resultado de la crisis creada por las personas seropositivas.

Hace siete años le diagnosticaron seropositivo a su marido, trabajador en una lienda. Ella no ha trabajado desde 1997. Era ama de casa y no sabía nada del SIDA hasta que su marido, cuando empezó a enfermarse, le informó sobre su diagnóstico médico. Ella se hizo la prueba y resultó seropositiva. Su marido toma anti-retrovirales cuando hay, y ella sabe que asf no puede seguir.

Lorena se gana la vida y obtiene las drogas para ella y su marido haciendo duros viajes en bus, cruzando las fronteras centroamericanas. Recauda el dinero de un grupo pequeño de nicaragüenses que quieren desesperadamente obtener drogas antiretrovirales. Negocia con los vendedores, a quienes encuentra a través de su extensa red de contactos entre personas seropositivas, en toda la región. Por ejemplo, en Guatemala, el sistema de salud ha creado un lucrativo mercado negro de medicinas antiretrovirales, que se venden públicamente en Irente de la clínica del SIDA del Instituto Guatemalteco de Seguro Social (IGSS).

Lorena se pegunta, “ ¿cómo puedo tener dudas sobre lo que estoy haciendo? Es nuestra única opción para poder vivir"

En su mensaje a la Reunión Extraordinaria de la Asamblea General de las Naciones Unidas, celebrada en junio, Juan Pablo II también habla del escándalo de esta desigualdad. Lamentando que en muchos países es imposible tratar a las personas con VIH por causa del alto costo de las drogas patentadas, el Papa recordó a Naciones Unidas que la Iglesia ha enseñado constantemente que existe una hipoteca social sobre todos los bienes particulares, y que el mismo concepto se debe aplicar a los derechos intelectuales. En la lucha contra el hambre, la enfermedad y la pobreza no puede tener vigencia sólo la ley de la ganancia.

6. Richard Stern, San José, Costa Rica, 21 de abril de 2000, publicado en Aff-AIDS Electronic Newsgroup, April 2000. 
El arzobispo Lozano, representante del Valicano en aquella asamblea, declaro:

Con demasiada frecuencia hemos dejado de levantar la voz para denunciar las injusticias estructurales y el pecado social, perpetuados por los programas dc ajuste estructural del Fondo Monetario Internacional y el sistema econóinico global que afecta directamente a los pobres. Los "países pobres muy endeudados" se están ahogando con una deuda impagable. [En América Lalina esto incluye a Bolivia, Honduras, Nicaragua y Guyana.]Por lo general, los países más pobres son también los más golpeados por la pandemia del VIH/SIDA. Con frecuencia, estos "países pobres muy endeudados" se enfrentan a una opción trágica: pagar la deuda o invertir el dinero en escuelas y centros de salud. El perdón de la deuda depende de que el país acepte los programas de ajuste estructural (los llamados ASAPS), dictados por poderes como el Banco Mundial y el Fondo Monetario Internacional. Para los países que enlrentan las condiciones de los ASAPS, esto significa recortes en subsidios para alimentación y bienestar social, y la introducción de cuotas. Es por eso que la deuda acelera la muerte de personas seropositivas en estos "países pobres muy endeudados". En este sentido, se puede decir que la deuda mata. La deuda, y el mantener la deuda de estos países, es un pecado, porque causa la muerte.

El economista Geoffrey Sachs, profesor de Harvard, en las reuniones del Organización Mundial de la Salud del año pasado recordó a su auditorio que para muchos de los países más pobres, la inversión del 3 por ciento de su PIB en salud significa 8 dólares por persona al año, comparado los 3,000 y 5,000 , dólares en los países ricos. Y añadió que

a veces, los críticos de la ayuda internacional sostienen equivocadamente que el problema fundamental de la atención de la salud en países pobres es la mala administración de los sistemas sanitarios. Quiero rechazar esta opinión en su totalidad. No se puede administrar un elicaz sistema de salud con solamente 8 dólares per capita. Y las sociedades más pobres del mundo que apenas sobreviven con el nivel actual de ingreso, o tal vez no sobreviven, no tienen cómo pagar mucho más con sus recursos actuales. Sobre todo, cuando el pago del servicio de la deuda a los gobiernos, al Banco Mundial y al Fondo Monetario Internacional supera los presupuestos anuales para atención de salud?.

\subsection{Desequilibrio de poder}

Una manifestación impresionante del desequilibrio de poder aparece en las relaciones entre los hombres y las mujeres:

7. Geoffrey Sachs. WHO Massive Elfort Campaign, Winterthur Health Forum, octubre, 2000. 
- Además de su vulnerabilidad biológica especílica para contagiarse del $\mathrm{VIH}$, las mujeres y las jóvenes enfrentan casi todos los días una relativa falta de control sobre su salud personal y su vida sexual, así como sobre la vida sexual de su pareja. No pueden negociar, ni rehusar, las relaciones sexuales dentro del matrimonio. Pero, con frecuencia, estas mismas mujeres son acusadas de ser porladoras del VIH, aun cuando hayan sido fieles a sus esposos, y aunque el virus hubiese entrado en el círculo familiar a través de la infidelidad de su marido.

- Al saber que sus mujeres e hijos tienen VIH, a veces los hombres abandonan a sus familias, no quieren hacerse una prueba de VIH y -lo que es más trágico- pueden comenzar relaciones sexuales con otras mujeres, continuando usí cl ciclo de transmisión de la enfermedad y la tragedia fámiliar.

- El machismo pone en peligro la vida: la vida de las mujeres, pero también la de los hombres, a quienes se exige que empiecen a tener relaciones sexuales desde muy jovenes, que tengan muchas parejas, que se arriesguen y que se crean que son invulnerables.

- Con demasiada lirecuencia, la pobreza fuerza a las mujeres y a los niños a prostituirse para poder mantenerse a sí mismos y a sus familias. En algunos casos, las familias obligan a sus hijas a la prostitución para poder pagar deudas o mejorar la seguridad económica de la familia. Las trabajadoras del sexo pueden estar en peligro de contagiarse del virus, o, si ya son seropositivas, corren el riesgo de transmitir la enlermedad a sus clientes. En determinadas circunstancias, las inujeres pueden ser reclutadas (con frecuencia transportadas de un país a otro) para convertirse en bailadoras exóticas o en empleadas domésticas, y descubren que han quedado atrapadas en una vida de prostitución con el riesgo de infección del VIH.

- La violencia sexual puede contribuir en muchas sociedades a la proliferación del VIH. En Sudáfrica, aproximadamente 370,000 mujeres son violadas cada año* . En Aınérica Latina, los prejuicios machistas influyen en la legislación sobre la violación. En catorce países de este continente, un hombre puede violar legalmente a su esposa o a su novia.

- El abuso sexual también ha crecido, debido a la misma pandemia del VIH, es decir, debido al esfuerzo para no contagiarse. Esto lleva a que, en muchas partes del mundo, los hombres no acudan tanto a prostitutas por temor a contagiarse. $Y$ la consecuencia es que muchos buscan los favores sexuales de mujeres jóvenes (pensando que no tendrán la infección).

8. Catholic Relief Services, Interim Standards and Approaches for CRS HIV/AIDS Programs in Africa, 16 de febrero, de 2001. p. 5. 
- El VIH/SIDA hace recaer sobre las mujeres y las jóvenes una mayor responsabilidad del cuidado de los alectados. Sc espera que las mujeres cuiden de los miembros enlecrmos de la lámilia, con lirecuencia sacrilicando su puesto de trabajo, $c$ incluso teniendo que buscar tratamiento médico para ellas mismas. Las lamilias aliectadas por el VIH, en la mayoría de los casos, retiran a las niñas del colegio para cuidar de sus padres o hermanos entermos del SIDA. Además de tenel que soportar la carga emocional, estas mujeres jóvenes pierden toda oportunidad para recihir una educación lormal, y por lo tanto. al acceso al empleo y it un luturo mejor.

En la XI Conferencia Intcrnacional del SIDA, en 1996, Richard Parker, Secrelario General de ABIA (Ascociación Interdisciplinaria del SIDA de Brasil), alirmó que enlocar cl problema desde la vulnerabilidad social y de género facilita una comprensión más abarcadora de las consecuencias: cl estigma sexual y la discriminación con que se cnl'rentan con tanta frecuencia los hombres homoscxualcs o trabajadores del sexo, las relaciones de poder y género, la opresión con que se enfrentan las mujeres y la marginación social y económica con que se enlirentan los pobres".

\subsection{Estigmatización y marginación}

Una reacción casi instintiva ante la infección del VIH ha sido discriminar y estigmatizar a las personas infectadas. Hay intentos para expulsar a los afectados por el virus $\mathrm{B}$ de pucblos, hospilales, colcgios, e incluso de comunidades cclesiales. Desalortunadamentc, hay algunos sacerdotes y pastores que se han negado a proporcionar asistencia pastoral o entierros religiosos a personas seropositivas. En algún momento. muchos gobiernos (nolablemente, en América Latina, el gobicrno cubano, por cjemplo) han practicado políticas de aislamiento forzoso y resiricción de movimiento a las personas seropositivas, inientras que otros, a veces, han permitido, y aun han apoyado, la violencia contra esas personas.

En general, ese comportaniento discriminatorio genera miedo y lleva a encubrir la enfermedad, aun entre aquellos que tienen un conocimiento básico de la pandemia. Estudios hechos en Costa de Marfil y Sudáfrica indican que en lugares donde hay una scroprevalencia muy alta, las mujeres se niegan a ser examinadas o no buscan los resultados de las pruebas. En Sudáfrica, un estudio sobre heridas causadas por jeringas descubrió que las enfermeras que las tenían no inforInaban a nadie, porque no querían someterse a pruebas del VIH. Según un estudio sobre atención comunilaria, menos de una de cada diez personas que cuidan a una persona seropositiva en el hogar diría que su pariente padece de SIDA"".

9. Richard G. Parker, "Empowerment. Community Mobilization, and Social Change in the Face of HIV/AIDS", ponencia presentada en la XI International Conference on AIDS, Vancouver, julio de 1996, pp. 6-7.

10. UNAIDS, 1999. 
Las personas seropositivas y estigmatizadas se encuentran con que se les niega atención, apoyo de su familia o de su comunidad, derechos sociales y legales, $y$, en algunos casos, la vida misma. Con demasiada frecuencia, a las personas seropositivas se les asigna el papel de víctima, indefensa, pasiva y necesitada, o se les asigna el papel de culpable.

Pablo Animaría del programa PROSA, en Perú, una contraparte de CAFOD, describe, con elocuencia, el camino que lleva de ser víctima a la realización personal:

Es relativamente fácil retomar control sobre la propia vida cuando las necesiJades básicas de la persona, vivienda, alimentación, vestido, trabajo y acceso a cuidados de salud y tratamientos, están cubiertas. Es más lácil sentirse activa y efectivamente parte de la respuesta al VIH/SIDA cuando alguien vive en una sociedad en donde se respetan las leyes, se permite el diálogo y en donde los ciudadanos están en una posición de igualdad unos con otros. En la mayoría de países, en el norte y en el sur, todavía persiste la discriminación y el aislamiento, y sigue siendo un sueño el acceso a un tratamiento adecuado y continuo.

Como personas con VIH/SIDA, nos hemos organizado para hacer campaña con quienes toman las decisiones para que se reconozcan nuestros derechos humanos fundamentales. Hemos tenido éxito en passes como Argentina, Brasil, Costa Rica, Panarná y Venezuela. La situación no es uniforme en toda Latinoamérica. Como personas infectadas, hemos tenido que crear respuestas que cubran nuestras necesidades, principalmente el que se nos reconozca de nuevo como individuos y no como personas con un específico estado de salud.

¿En qué momento preciso empezamos a comprendernos como víclimas? En primer lugar, al aceptar que el paradigma médico es una realidad que no se pucde carnbiar; dentro de este paradigma, cl VIH nos convierte en seres infecciosos, potencialmente peligrosos. Aspectos importantes de nuestra vida. tales como nuestra sexualidad o reproducción, pasan a ser objelo de escrutinio público. Dejamos de ser nombres y pasamos a ser números. Este sentimiento de scr víctimas nos convierte en objetos más que en actores y defensores y inerma nucstra fortaleza y nuestro deseo de vivir.

La capacidad de las personas con VIH/SIDA para asumir la autoresponsabilidad puede mejorar cuando la comunidad les ofrece:

- Intormación correcta sobre los riesgos y las alternativas relativas al VIH/ SIDA, y acceso a intormación y mélodos para la próctica de una sexualidad madura y segura.

— Igualdad de oportunidades para oblener servicios y cuidados apropiados.

- Leyes que protejan la individualidad, la privacidad y la confidencialidad 
de las personas con VIH/SIDA y sus familias, evitando la criminalización y el aislamiento.

- Oportunidades para crear grupos que ofrezcan apoyo emocional y ayuda mutua. Oportunidades para personas con VIH/SIDA de contar sus historias como insirumento para la recuperación personal y para paticipar en una comunidad más amplia.

- Quizás no podemos hablar de potenciar a las personas VIHpositivas en Latinoamérica o Alrica, pero podemos tratar de dar a las personas que viven con VIH/SIDA una oportunidad para articular su propia voz y desarrollar sus propias formas de actividad. Puede que esto no nos lleve a un paseo lleno de éxitos en el camino político, pero el encontrar nuestra propia voz, mejorará nuestras condicioncs de vida.

\subsection{Intimidad, confidencialidad y responsabilidad}

Otro problema ético con relación a la pandernia tiene que ver con el derecho a la confidencialidad de todas las personas con respecto a los detalles íntimos de sus vidas. Debido a la ignorancia y el miedo, muchas personas, incluyendo ciertos iniembros del clero, creen quc el VIH puede propagarse por contacto social o a través del aire, y que por elio se debe revelar la identidad de personas scropositivas y así evitar contagiarnos.

En vez de adoptar y seguir rigurosamente las medidas de precaución universales (es decir, políticas de asistencia sanitaria para protegerse del contagio del VIH u olras cnlermedades, llevadas en la sangre de cualquier paciente), entre el personal médico pucde haber quien cree que necesitamos tomar medidas extraordinarias para cuidar a pacientes que se saben o sospechan que son seropositivos. Al Jescuidar los derechos del paciente a la confidencialidad, tales temores y políticas irracionales dañan la dignidad y los derechos humanos de codos.

A su vez, las personas seropositivas deben reconocer su responsabilidad de informar a las personas en peligro de contagio, sobre todo en el caso de una relación scxual.

En conclusión, varias cucstiones importantes y de carácter ético surgen de la pandemia del VIH/SIDA:

- los más pobres y marginados son tambićn los más vulnerables al VIH;

- las personas débiles o sin poder, sobre todo las mujeres en las comunidades pobres, sufren también desproporcionalmente los electos del VIH;

- la cpidemia ha sido la razón para la discriminación injusta y la esligmalización; 
- es común el abuso de los derechos de los pacientes a la intimidad y la conlidencialidad.

\subsection{El uso de preservativos en la prevención de la transmisión del VIH}

El inedio inás común de transmisión del VIH proviene de las relaciones sexuales de hombre a mujer, mujer a hombre, hombre a hombre, y (muy raramente) de mujer a mujer. Por ello tal vez el asunto ético más crítico y discutido sobre la prevención de la Iransmisión del VIH se centra en la legitimidad del uso del preservativo para reducir el riesgo de infección. Cuando los cientfficos sugirieron que el uso correcto de un condón de látex de alta calidad podría reducir el riesgo de transmisión del VIH durante las relaciones sexuales se suscitó un gran interés público en la promoción de esıa forma de prolección. Desafortunadamente, muchos de los esfuerzos iniciales de educación preventiva se centraron casi de Corma exclusiva en este método y no mencionaron que las maneras más cficaces para prevenir la transmisión sexual del VIH son la abstención del sexo antes de casarse $y$ la fidelidad dentro del matrimonio de los dos esposos no inlectados.

Los líderes católicos y de otras religiones protestaron contra la promoción masiva de los preservativos por medio de programas que no discutían otros mélodos de prevención, basados en valores. La preocupación de los líderes de la Iglesia consiste en que de esta forma se ayuda a promover relaciones sexuales extra-maritales y a asegurar la promiscuidad sexual. No es nada sorprendente que inuchos hayan visto una relación entre estas preocupaciones y la prohibición de la Iglesia del uso de anticonceptivos artificiales.

La postura firme y pública de la Iglesia en contra del uso de los condones ha fomentado en los educadores sobre el VIH, algunos gobiernos, muchos profesionales de la salud y los medios de comunicación, la opinión de que la Iglesia católica impide los esfuerzos de prevención del VIH y, por lo tanto, promueve la muerte".

Pero junto al continuo debate teórico sobre la legitimidad de educar sobre el uso del condón como medida preventiva, está la experiencia diaria de los profesionales católicos, agentes de pastoral y de la salud, quienes se enfrentan al angustioso problema de no saber qué decir a las personas que buscan su ayuda.

Hay muchas preguntas. Si se debe ocultar la información a una persona inlectada casada, que se siente que no está lista para revelar su condición a su cónyuge, sobre todos los métodos de prevención. Si se debe orientar a una pareja casada —n la que uno está infectado- a arriesgarse a morir, si deciden seguir

11. Mons. Jacques Suaudeau (Pontifical Council for the Family), "Prophylactics or Family Values: Stopping the Spread of HIV/AIDS", L'Osservatore Romano (edicion semanal), N. 16. 19 de abril de 2000. 
con las relaciones sexuales, porque eso les ayuda a aguantar el dolor físico, psicológico y espiritual de vivir con la inlección del VIH en su vida familiar. Si se deben cerrar los ojos ante las necesidades de una mujer que ha sido vendida $u$ obligada o lorzada por la pobreza a una vida de prostitución, que desea reducir el peligro de contagiarse de este virus mortal.

\section{Valores humanos y medidas de prevención pragmáticas}

Por lo general, todas las partes están de acuerdo en que hay que ir a las raíces de la vulnerabilidad para frenar la propagación del VIH: enfrentar Iradiciones culturales y las desigualdades de género, promover una economía que permita la plena dignidad y la igualdad de todos, valorar el papel primordial del matrimonio y de la familia en la estabilización y construcción de cualquier sociedad ${ }^{\prime 2}$.

Sin embargo, además de las soluciones que humanizan a largo plazo y que son verdaderamente preventivas, son también necesarios los esfuerzos a corto plazo, dirigidos a frenar la propagación de la infección, si es que queremos en realidad proteger la vida humana. Esto incluye actividades educacionales, que huscan reducir el número de parejas sexuales de una persona, postergar la primera relación sexual y, cuando no se puede persuadir a los individuos a que se abstengan de estas relaciones antes de casarse, a usar preservativos durante el aclo sexual. En esle sentido se puede decir que el uso del condón no es anticonceptivo, o que vaya contra la concepción, sino que es anti-mortivo, es decir, que vá contra la muerte.

En palabras de monseñor Lester Guilly, en aquel entonces obispo emérito de Georgetown, Guyana: "Me siento obligado a concluir que cuando una pareja ha decidido definitivamente pecar contra el sexto mandamiento, no debemos animarles a que violen también el quinto".

El cardenal Arns, en un entrevista por radio, dijo que lo más importante es cvilar, primero, el genocidio, después, el homicidio, y, por último, el suicidio. Lucgo podremos preocuparnos sobre si es lícito o no el uso del preservativo.

La pandemia del SIDA es una tragedia social, económica y humana sin precedentes, que afecta no sólo a los millones de personas infectadas y afectadas por el VIH. sino a toda la familia humana. Realmente, el cuerpo de Cristo liene SIDA.

12. Mid.. Mons Suaudeau dice en su artículo: "Se puede entender lo que motiva a las atutoridades de salud a distribuir los profilácticos a las prostitulas y sus clientes. Pero la prevención del VIH debe comprender más que esto; debe alcanzar otros niveles y adenirarse en las verdaderas raíces sociales. cconómicas, políticas y morales de la epidemia... Donde hay una formación verdadera sobre los valores de la lamilia, la lidclidad, la castidad matrimonial, el verdadero sentido del regalo muluo de sí mismo -y csto incluye también al Estado- y donde superan formas intrusas de la promiscuidad. la gente logrará una victoria humana, aun sobre este terrible fenómeno". 
Los inedios de comunicación. los gobiernos del mundo, ONUSIDA, agentes de salud y de pastoral, y otros en la vanguardia de la lucha contra el SIDA miran a la Iglesia y sus líderes y les piden un compromiso permanente y conslructivo con estrategias de atención y prevención.

\section{Conclusión}

Para terminar, quisiera compartir las siguientes conclusiones y preocupaciones que hemos identificado durante catorce años de labor de Caritas en búsqueda de una respuesta enérgica de la Iglesia católica para las hermanas y los hcrmanos que viven con el VIH/SIDA.

Fiel a su misión evangelizadora, la Iglesia -el clero y los laicos- está llamada a responder con un amor incondicional, atendiendo sin prejuicios y apoyando pastoralmente a los que viven con VIH o SIDA; a defender sus derechos y su clignidad, y a proteger y fomentar el bien común y global a través de prograinas que combaten el avance de la pandemia y de servicios de apoyo de la Iglesia a actividades eficaces de prevención.

Dada la magnitud y prevalencia del VIH/SIDA en Africa y en otros lugares, la Iglesia reconoce la necesidad de medidas urgentes para reducir los riesgos, como parte de una respuesta necesaria a esta emergencia de salud pública.

A largo plazo, la medida más importante y fundamental para reducir la propagación del VIH consiste en un cambio cultural y -concomitantemente- de comportamiento en el campo sexual. La Iglesia debe continuar cooperando con las autoridades públicas para asegurar que el cambio de comportarniento a largo plazo sea una dimensión integral de cualquier campaña para la reducción del ricsgo.

La Iglesia debe conlinuar defendiendo y promoviendo los valores encarnados en su enseñanza de abstención sexual antes de casarse y de fidelidad matrimonial. Por olra parte, es claro que los cambios culturales no ocurren de la noche a la mañana, y el cambio de comportamiento es un proceso de largo plazo que raramente se logra con rapidez.

Existc una pluralidad de posiciones entre los líderes de la Iglesia con respec10 a los varios métodos para prevenir la transmisión del VIH durante las relaciones sexuales. En la arena pública, la Iglesia debe continuar reconociendo lo complejo y complicado de la cuestión de la prevención del VIH. Hay que evitar que se Ilcgue a una "parálisis (o miedo) del condón"l?, porque esto obstaculiza-

1.3. "El condón paraliza a las organizaciones de la Iglesia". Condom paralysis (en inglés) se reliere al miedo de las organizaciones vinculadas a la Iglesia a comprometerse en cualquier aspecto de la prevención, educación o atención en respuesta al PVVS, donde exista la posibilidad de verse obligadas a discutir el tema del uso de los conclones para prevenir la transmisión del VIH. 
ría una respuesta elicaz a la pandemia del VIH/SIDA de parte de las organizaciones de la Iglesia.

Mientras la Iglesia nunca puede decir que cl condón facilita el sexo seguro, hoy liene que reconocer que el uso de preservativos reduce el riesgo de la transmisión sexual del VIH. Se debería ofrecer información correcta y completa sobre todos los métodos de prevención del VIH, en los programas de educación, y la educación sexual debería comenzar en las escuelas, en los años antes de la pubertad.

La Iglesia debería olrecer información honesta, en el ámbito externo de la cducación, y apoyo y orientación en el ámbito interno, para poder capacitar a las personas a que ellas mismas tomen decisiones, con contianza, sobre la prevención de la transmisión del VIH.

Como defensora de los pobres y de los que están imposibilitados para ello, la Iglesia debe denunciar las injusticias esıructurales que impiden el cambio de comportamiento personal y debe trabajar incansablemente para resolverlas. En un mundo acostumbrado a soluciones instantáneas, la Iglesia debe tener el valor para llamar la atención sobre las injusticias de la sociedad y dentro de sus propias instituciones, las cuales impiden que las personas se orienten según esos valores.

En este continente nació un proceso tcológico basado en el discernimiento de la Palabra de Dios, desde la realidad vivida por los oprimidos. En esa tradición, la Iglcsia en América Latina tiene que escuchar los signos de estos tiempos nuestros y anunciarlos: signos que indican que el VIH y el SIDA son o serán también nuestro problema. Esto es muy importante, sobre todo en los lugares donde la epidemia es más silenciosa o es desconocida. El camino a la liberación. en beneficio de las personas más marginadas y junto con ellas, debe incluir la liheración de las injusticias que han sacado a luz el VIH y el SIDA. El VIH ya está presente en este camino de liberación. Como dijo Mons. Romero:

No se puede separar la palabra de Dios de la realidad histórica en que está proclamada. No sería la palabra de Dios. La Biblia sería nada más que un libro piadoso de historia en nuestra biblioleca. Es la palabra de Dios porque ilumina, contrasta, rechaza y alaba lo que está pasando en nuestra sociedad hoy en día (27 de noviembre de 1977).

Sencillamente. el VIH/SIDA es lo que está pasando en nuestras sociedades hoy en día.

Todavía hay tiempo para dar una respuesta. América Latina puede aprender de las experiencias de los países y continentes donde la epidemia lleva muchísimos años. A su vez, América Latina puede aportar sus propias reflexiones, sus experiencias y su voz para sumarse al esfuerzo mundial para responder a este problema, que es de lodos. Como nos recuerda un proverbio africano: "el mejor momento para plantar el árbol fue hace veinte años. Después, el mejor momento es ahora mismo". 